\title{
Review of food challenges in a pediatric tertiary care centre
}

\author{
Alison Haynes ${ }^{1 *}$, Wade Watson², Gregory Rex², Sandeep Kapur ${ }^{2}$ \\ From Canadian Society of Allergy and Clinical Immunology Annual Scientific Meeting 2010 \\ Victoria, Canada. 3-6 November 2010
}

\section{Background}

Oral food challenges are essential to determine when foods can be safely reintroduced in children with diagnosed food allergies. Identifying risks for failed challenges and severity of reactions is important for continuing safe practices.

\section{Material and Methods}

A retrospective chart review from January 2008 to March 2010 was conducted. Data extracted included age, food tested, ImmunoCAP level, reaction, type of symptoms and treatment received.

\section{Results}

Of 322 challenges (median age 4.8 years), 204 (63\%) passed, $89(28 \%)$ failed and $29(9 \%)$ refused to complete the challenge. Passed challenges included 54 (26\%) egg, $52(25 \%)$ peanut, 32 (16\%) milk, 22 (11\%) tree nuts, 17 (9\%) fish and shellfish and 27 (13\%) others. Failed challenges included 43 (48\%) peanut, 17 (19\%) egg, 12 (13\%) milk, 5 (7\%) tree nuts, 4 (4\%) fish and shellfish and 8 (9\%) others. ImmunoCAP medians for passed challenges were peanut $0.35 \mathrm{KU} / \mathrm{L}$, egg $0.45 \mathrm{KU} / \mathrm{L}$ and milk $0.35 \mathrm{KU} / \mathrm{L}$. Failed challenges ImmunoCAP medians were peanut 0.74 $\mathrm{KU} / \mathrm{L}$, egg $0.95 \mathrm{KU} / \mathrm{L}$ and milk $0.97 \mathrm{KU} / \mathrm{L}$. Symptoms included 77 (86\%) cutaneous/mucus membrane, 8 (9\%) respiratory and $19(21 \%)$ gastrointestinal. No patients had cardiovascular symptoms. Epinephrine was required to treat $14(16 \%)$, prednisone in $10(11 \%)$, antihistamine in 49 (55\%) and bronchodilator in $2(2 \%)$ reactions. 35 (39\%) of patients did not require any treatment. There were no hospital admissions or deaths reported.

* Correspondence: haynesalison@yahoo.com

'Department of Pediatrics, Memorial University, St. John's Newfoundland

Full list of author information is available at the end of the article

\section{Conclusions}

Reactions associated with controlled food challenges are frequently mild and reversible with treatment. ImmunoCAP levels in successful challenges tend to be lower compared to failed challenges.

\section{Author details \\ ${ }^{1}$ Department of Pediatrics, Memorial University, St. John's Newfoundland. \\ ${ }^{2}$ Department of Pediatrics, Dalhousie University, Halifax Nova Scotia.}

Published: 4 November 2010

doi:10.1186/1710-1492-6-S2-P2

Cite this article as: Haynes et al:: Review of food challenges in a

pediatric tertiary care centre. Allergy, Asthma \& Clinical Immunology 2010 6(Suppl 2):P2.
Submit your next manuscript to BioMed Central and take full advantage of:

- Convenient online submission

- Thorough peer review

- No space constraints or color figure charges

- Immediate publication on acceptance

- Inclusion in PubMed, CAS, Scopus and Google Scholar

- Research which is freely available for redistribution 